\title{
The Implementation of the Double Reduction Policy Problems, Causes, and Suggestions
}

\author{
Lihua Zhang* \\ Nanjing Yutong Experimental School, Nanjing 210000, Jiangsu, China \\ *: All correspondence should be sent to: Lihua Zhang. \\ Author's Contact: Lihua Zhang, E-mail: 2575745583@qq.com \\ DOI: https://doi.org/10.15354/si.22.or010 \\ The authors declare no competing interest
}

The Double Reduction policy tries to alleviate the academic pressures that homework and off-campus tutoring services place on students. Since its implementation half a year ago, the policy has relieved students of some of their heavy workloads. However, there are still policy infractions all around the country. The issues that arise during policy implementation are summarized and their causes are examined in this study. Suggestions are made in order to fulfill the policy's objectives.

Keywords: The Double Reduction Policy; Off-Campus Tutoring; After-School Training Institutions; Student Workloads; Reduction in Academic Burden

Science Insights, 2022 February 28; Vol. 40, No. 3, pp.457-461.

(C) 2022 Insights Publisher. All rights reserved.

Creative Commons Non Commercial CC BY-NC: This article is distributed under the terms of the Creative Commons Attribution-NonCommercial 4.0 License which permits non-commercial use, reproduction and distribution of the work without further permission provided the original work is attributed by the Insights Publisher.

Introduction

$\mathrm{M}$ ANY parents enrolled their children in off-campus tutoring courses, and generations of students were burdened with heavy workloads and blindly invested time and energy in tutoring materials and tests. Over the years, students, parents, teachers, and intellectuals have made appeals to ease the academic burden on pupils. In this backdrop, on July 24, 2021, the Chinese government issued Opinions on Further Reducing the Burden of Homework and Off-Campus Training for Compulsory Education Students (often referred to as the Double Reduction policy). The establishment and implementation of the Double Reduction policy initiated the new era's most severe and far-reaching academic burden alleviation program. Its purpose is to ease students' excessive academic burdens in order to protect their physical and mental health, alleviate parents' concerns, and enhance the overall quality of school education.

However, the policy's implementation during the last six months reveals that it is relatively simple to alleviate homework burdens, whereas regulating after-school tutoring is a difficult effort that requires long-term research. This study seeks to document the difficulties encountered during the earliest stages of implementing the Double Reduction strategy and to explain the underlying causes of these difficulties. Additionally, it makes several recommendations for effectively reducing students' excessive academic burdens. To accomplish the policy's objectives, governments at all levels must strengthen the regulatory framework and foster coordination among numerous agencies in order to raise the overall quality of education in China.

Issues That Arise During the Implementation of the Strategy of Double Reduction

Despite the Speed and Tenacity with Which the Law Was Implemented, It Did Not Endure Long, and Off-Campus Tutoring on Weekends, National Holidays, and during the Winter Vacation Continues to Be Popular among Students. 
Many after-school training institutions have had to lay off teachers or face bankruptcy as a result of the Double Reduction policy, and even giant training institutions such as New Oriental Group and TAL Education Group are struggling for survival, which appears to be a sign of the education and training industry's demise in China. However, if we shift our attention away from Beijing, Shanghai, and Guangzhou and toward other firstand second-tier cities, and away from after-school training behemoths like New Oriental and TAL and toward a plethora of medium-to-small-scale institutions, we see a very different environment. Off-campus tutoring is still thriving, and medium-to small-sized universities are recruiting students and teachers via recruitment tools or their own websites.

The Double Reduction policy prohibits advanced teaching, subject-based training from non-subject-based training institutions, after-school training institutions from organizing "subject-based" training programs during national holidays, weekends, or winter or summer breaks, and in-service teachers from engaging in off-campus tutoring, among other things. The importance of enforcing the Minors Protection Law is highlighted (1). At the provincial and municipal levels, there are also laws and regulations governing how the Double Reduction program should be implemented. For instance, the Jiangsu Provincial Department of Education's Notice on the Work of Primary and Secondary Schools and Kindergartens The 2022 Winter Vacation has the following provisions regarding the Double Reduction policy: it is strictly banned for schools to use the winter vacation to conduct subject-based tutoring; subject-based tutoring programs for compulsory education students conducted by offline training institutions should be prohibited; subject-based training (including foreign language training) for preschool children aged three to six years should be prohibited; and non-subject-based training institutions should refrain from conducting subject-based tutoring in the name of competence development and thinking training. In response to these policies, public schools across the country implemented steps such as reducing student workloads, prohibiting teachers from disclosing students' test results, and offering after-school care in the second half of 2021. These measures have resulted in positive consequences. Meanwhile, training institutions have changed tutoring schedules in response to the government's request.

Nonetheless, after a half-year, after-school training institutes appear to have reverted to their previous practices. To gather first-hand information, the author once applied for a position as a Chinese tutor at a Nanjing-based training institution. When explaining the tutor's working hours during the interview, an institution staff member stated plainly that the tutor could only take one day off per week and work all day on Saturdays and Sundays, and that pertinent tutoring should be conducted to improve students' academic achievements, or test scores. Thus, we feel that significant progress must be made before the after-school burdens of compulsory education children are significantly alleviated.

\section{Off-Campus Tutoring by In-Service Teachers Continues to Occur.}

One of the fundamental components of the Double Reduction policy is the control of in-service instructors' engagement in off-campus tutoring. Participation of in-service teachers in off-campus tutoring jeopardizes educational equity and quality, as participating teachers may purposefully overlook critical knowledge points in class for their own benefit, which has been one of the primary reasons for parents' lack of confidence in school education and the dramatic growth of the after-school training industry. Under the policy of the Double Reduction, in-service teachers are required to resign from parallel positions at after-school training institutions. Yet another concerning trend emerges: teachers swap after-school tutoring for their own children or give private after-school tutoring to acquaintances' children. On the Internet, there were instances of parents contacting teachers for after-school tutoring for their children using unique connections. These stories are reasonable in some ways, because most teachers, as parents of their own children, are naturally in need of after-school tutoring services and are unable to disregard traditional social bonds. On the other hand, if instructors' children and the children of their contacts benefited from specialized private tutoring, the rest of the students would be disadvantaged and eventually fall behind. This has a detrimental effect on educational equity and defies the policy's aim.

\section{Since the Implementation of the Double Re- duction Policy, Not All Primary and Secondary School Students in China Have Been Relieved of Onerous Academic Burdens.}

The government's policy is insufficiently specific and comprehensive and must be supplemented by actual and implementable initiatives from local governments. As a result, the policy's efficacy differs across provinces and cities with varying economic, cultural, and educational levels. Developed regions such as Jiangsu and Shanghai can propose comprehensive rules governing school administration, assignment design, examination systems, and monitoring procedures to assure the policy's proper execution. However, due to the more pressing needs of economic development and higher education, local governments in those second- and third-tier cities are less likely to take concrete steps toward implementing the Double Reduction policy. As a result, the academic burden on primary and secondary school students has not been reduced uniformly.

\section{The Causes of the Problems}

\section{Low Acceptability of the Policy to Relevant People}

The Chinese government began regulating after-school training institutes in early 2000. As the academic pressure on pupils increased, the government decided to implement a thorough regulation of after-school training programs for elementary and secondary school students in 2018. Ironically, we see in retrospect that China's after-school training business boomed from 2000 to the year of the Double Reduction policy's implementation. This phenomenon, which contradicts educational policies, implies that those who are subject to them, including but not limited to parents, students, and teachers, are unaware of them (2).

Over the last two decades, China has experienced fast economic growth and an ever-increasing demand for highly educated professionals. Additionally, there are striking inequalities 
in living standards among people with varying educational degrees. In this climate, the dogma of "to enroll in a top-tier university and find a good job" has been a dogma for generations of parents and students. Additionally, many parents missed out on higher education when they were younger for a variety of historical reasons and have been working in low-wage jobs and working long hours to support their children. Naturally, they wish for their children to achieve a higher level of education, a better career, and a better life. The benefits of after-school training institutions are well accepted by these parents because they can quickly compensate for their children's deficiencies in specific subjects and improve their academic performance in order for them to enter satisfactory high schools and universities via entrance examinations. These parents' expectations align with the benefits of training institutions, which explains their opposition to regulation of after-school training institutions. Similarly, pupils who understand the significance of academic performance and are enthusiastic about learning would seek assistance from after-school training institutes regardless of burden relief programs.

\section{Parents' and Students' Major Concerns Re- main Untouched.}

The policy of Double Reduction does not alleviate academic anxiety for parents and children, as the difficulty of high school and college entrance examinations has never decreased. Students face stiff competition in two highly competitive entrance examinations. Secondary education in China is structured according to the General-to-Vocational Student Roughly Equivalent (GVRE) policy, which mandates that approximately $50 \%$ of junior high students attend general high schools and the remainder attend secondary vocational schools. Their high school entrance exam scores are used to identify the type of school they will attend. Students compete in the hyper-competitive college entrance exams (dubbed "Gaokao" in Chinese) for admission to a select number of prestigious universities.

Parents are hesitant to enroll their children in vocational education due to deep social prejudices against it and the inadequate educational circumstances in the majority of vocational institutions. It is legitimate for parents to be concerned that their children will become less competitive as a result of the Double Reduction policy and will be unable to enter trade schools unless some of their peers discreetly accept private coaching. These issues contribute to the continuation of after-school training establishments operating under different titles.

Furthermore, as a result of China's uneven growth in compulsory education, the educational level of public schools in undeveloped areas is often low, making it impossible for children to acquire sufficient knowledge. As a result, they lag behind their developed-area counterparts who have access to high-quality educational resources (3). Private tutoring supplied by highly qualified teachers employed by high-paying after-school training institutions becomes a significant supplement to classroom instruction, attracting pupils in need of tutoring services.

Educational parity is a critical factor in determining a country's progress and social stability. Educational equity needs the collaboration of numerous agencies across the entire society.
How, in the current climate of limited admissions to ordinary high schools and universities, are so many failed pupils to be rehabilitated? How can we make upward social mobility more accessible to people who have failed? How can we successfully address the legitimate concerns of parents and children in order to alleviate the educational burden? These issues cannot be resolved alone by the Double Reduction policy. Rather than that, they are the obstacles impeding the policy's effective execution.

\section{The Lack of Efficient Regulatory Mechanisms}

Since the Double Reduction policy was implemented, excessive off-campus tutoring has been curtailed. However, it takes time for government agencies to develop particular measures to address the diverse array of after-school training institutions and oversight systems to monitor the regulatory process and outcomes (4).

According to the Education Law, the Law on the Promotion of Private Education, the Administrative License Law, and the Regulations on the Implementation of the Law on the Promotion of Private Education, an after-school training institution classified as a private school may apply for approval to the local Department of Education, the Administration of Industry and Commerce, or the Administration of Labor and Social Security. Due to the lack of a dedicated department for approving after-school training institutions, the department of education must communicate with several other departments in the regulation process due to the institutions' unique operating characteristics, which impairs the governance's efficiency and effectiveness. For instance, if an after-school training facility registers with the Administration for Industry and Commerce as a commercial institution, the department of education will be unable to impose effective surveillance on it. Additionally, China's common concerns include an unclear division of responsibility and communication difficulties between several ministries. These characteristics result in several approvers but no regulators for after-school training organizations.

\section{Suggestions for the implementation of the Double Reduction policy}

\section{To Define the Role of After-School Training Institutions and Optimize the Regulation Mechanism}

Education encompasses not only public schooling, but also private education, distance education, and online education. Off-campus tutoring is a critical component of private education, which serves as an excellent supplement to public education. It is possible to tailor tutoring to meet the unique needs of each student. Given the benefits of off-campus tutoring, authorities should recognize the necessity of after-school training institutes and the legitimate need for off-campus tutoring by parents and kids. Rather than taking a one-size-fits-all strategy, the government is likely to address off-campus tutoring on a case-by-case basis, taking into account the unique circumstances in different locations. Having stated that, after-school training programs should not be used as battlegrounds for examination-based education. Rather than being the cause of educational unfairness and widening differences between rural and urban education, 
they should work to improve the nation's overall educational quality.

To maximize the regulatory process, the government should entrust educational authorities at all levels with the administration of existing education and training institutions; these authorities should be responsible for the approval, supervision, and regulation of training institutions. Now that the Double Reduction policy has reclassified after-school training facilities as non-profit organizations, educational authorities should tighten their oversight of tuition costs. Regular online verification and random inspection of teacher qualifications should be conducted to verify that teachers with teaching certificates operate in after-school training establishments. Fake advertisements of off-campus tutoring results and excessive packaging of educational institutions must be prohibited. Subject-based and non-subject-based training should adhere to the policy's tight rules (5).

\section{To Integrate the Efforts of Multiple Agencies and Promote the Transformation of Social At- titudes}

As previously stated, one of the primary reasons for the difficulties in implementing the Double Reduction policy is that it does not address the primary concerns of parents and kids. The policy is simply a stopgap measure to alleviate the educational strain. To address the issue fundamentally, we should work to modify social attitudes and conduct in-depth economic and cultural studies (6).

Most crucially, individuals should abandon the long-held belief that a school-progression-oriented general high school education is far preferable to a job-oriented vocational education. Both general education and vocational education are critical components of national education, serving as major engines of economic development in China. Educational authorities should make greater efforts to improve vocational education by hiring highly qualified teachers, improving educational conditions in vocational schools through regulatory changes, and collaborating with businesses to upgrade learning settings for vocational school students.

The poor social position of regular employees exacerbated the persistent bias against vocational education in the twentieth century. However, China is undergoing an industrial transition, and certain industries are experiencing workforce shortages due to the retirement of older generations of employees. The country is eager for highly skilled personnel to carry out the transformation of industrial chains from low-end to high-end and to compensate for the manpower deficit. Given this, relevant government agencies should foster collaboration between vocational schools and related businesses in order to prepare students to be technical and skilled workers, thereby improving workers' social position.

\section{To Promote the Balanced and High-Quality Development of Compulsory Education to}

\section{Raise Compulsory Education Standards}

Students' subject deficiency as a result of inadequate school education is a primary cause of their engagement in off-campus tutoring. Following the implementation of the Double Reduction policy and the ensuing crackdown on off-campus tutoring, it has become critical to increase the quality of compulsory education in order to meet students' need for overall academic performance improvement (7).

Although China has a high degree of universalization of compulsory education, due to the country's enormous territory and uneven economic development in various sectors, the unequal development of compulsory education has long been a severe concern. The educational level of public schools in first-tier cities such as Beijing, Shanghai, and Guangzhou is much higher than that of public schools in second- and third-tier cities, where off-campus tutoring was once a critical supplement to school education. To properly implement the Double Reduction policy, the government should strengthen compulsory education development procedures and optimize the use of regionally superior educational resources. To begin with, the two-way interchange of urban and rural compulsory education instructors should be reinforced, and teacher and principal rotation within counties or municipal districts should be encouraged, in order to address the issue of the unequal distribution of high-quality human resources across schools. Additionally, new school operating models such as inter-school alliances and educational conglomerates led by major schools should be encouraged, and platforms for inter-school exchange and collaboration should be established to facilitate the sharing of high-quality educational materials. Additionally, poor schools should receive particular assistance, such as the assignment of experienced administrators and outstanding instructors, as well as repairs or upgrades to school facilities, teaching tools, and other equipment (8).

Whatever the after-school training business develops, school education continues to dominate China's existing education system. Enhancing the quality of compulsory education is critical not just for implementing the Double Reduction policy but also for achieving educational parity in China.

In conclusion, implementing the Double Reduction policy on a national scale will provide obstacles. It is intended to relieve children of excessive academic responsibilities in order to free them up to participate in other useful activities such as housework, athletics, and creative training. Nobody benefits from subject-specific after-school tutoring unless everyone participates. The Double Reduction policy is a decisive attempt to put an end to destructive rivalry, or involution. Nonetheless, simply reducing homework and prohibiting after-school tutoring is insufficient. We must first determine the true sources of these burdens and then apply the appropriate remedies. It will require the concerted efforts of the entire society to equalize educational resource allocation, substantially improve educational quality standards, and shift public attitudes toward education and its worth. 


\section{References}

1. Ministry of Education. Ministry of Education and other three departments answering reporters' questions on the Notice on Effectively Reducing the Burden of Off-campus Tutoring of Primary and Secondary School Students and Carrying out Special Actions Regulating After-school Training Institutions. Basic Educ Rev 2018; 2018(8):3-5.

2. Yang ZL. The dilemma of the regulation of after-school training for primary and secondary school students and solutions. Guizhou Norm Univ 2020; 2020:49-51.

3. Hu TY. The regulation and governance of education and training institutions in China. Educ Res Monthly 2013; 2013(7):14-19.

4. Zhu YM, Li MJ, Xu Y. The educational orientation and governance of after-school training institutions. Issue Juv Crim Delinq 2020; 2020(4):44-52. DOI: https://doi.org/10.3969/j.issn.1006-1509.2020.04.006
5. Ouyang CY, Qiu T. The problems in the implementation of the regulatory policy of after-school training institutions and solutions. J Curricul Instruct 2020; 2020(10):86-89.

6. Yang C. The Dilemma of governance of after-school training institutions and implementation measures. Sch Admin 2022; 2022(1):32-35.

7. Peng CM. The burden is reduced, and the quality is increased. Panzhihua Daily, January 4, 2022; 2022 (001). DOI: https://doi.org/10.28615/n.cnki. npzhb. $\underline{2022.000031}$

8. Zhou HY, Qi YL. The implementation of the Double Reduction policy: Focuses, difficulties, and suggestions. J Xinjiang Norm Univ (Phil Soc Sci Ed) 2022; 2022(1):1-11. DOI: https://doi.org/10.14100/j.cnki.65-1039/g4.20211022. 001

Received: December 20, 2021 ｜ Revised: January 10, 2022 ～Accepted: January 16, 2022 